\title{
Low-Energy Parking Structure Design
}

\section{Overview}

This guide provides design teams with best practices for parking structure energy efficiency in the form of goals for each design aspect that affects energy use.
A parking structure typically uses $5 \%-20 \%$ the energy of its supported building (or buildings). This potentially small and removed energy use can be lost in the periphery of energy efficiency efforts. Parking structures should not be overlooked, though, because the savings potential is immense. Energy use can be reduced by more than $90 \%$ over a baseline parking structure ${ }^{2}$ with typical construction costs.

To achieve the U.S. Department of Energy (DOE) goals of energy security and environmental quality, you should encourage the use of public transportation and other transportation alternatives. Parking locations are necessary, however, to provide access to public transportation spokes and walkable areas. Parking structures also have some advantages over parking lots: they reduce the footprint and may reduce light pollution. The intent of this guide is to demonstrate that parking structures can be designed and operated very energy efficiently.

This guide is intended for new construction (NC), standalone, self-park structures; however, many of the recommendations can also apply to retrofit (R) and mixed-use structures. Design considerations include safety, ease of travel for drivers and pedestrians, space efficiency and compatibility with vehicle types, aesthetics, integration with surrounding streets and buildings, and operations and maintenance (McDonald 2009). An integrated team is required to successfully balance these considerations. To achieve the stated energy savings potential, all team members must add energy savings vigilance to their list of responsibilities; this guide can serve as an energy efficiency goal- setting resource.

\section{Design Considerations $\nabla$}

The following sections provide energy savings goals and design considerations, broken out by building systems and steps of the design process. Building systems addressed are ventilation, daylighting, electric lighting, miscellaneous equipment, and renewable energy. System-specific energy savings are given to highlight the potential of each consideration and to provide goals for system-by-system retrofit scenarios. The $90 \%$ energy savings relative to an ASHRAE Standard 90.1 2007 baseline applies to the combined package of all the most aggressive recommendations in this guide. Onsite renewable energy, commissioning, and M\&V are also addressed as a means to work toward net zero energy and to realize the energy saving goals.

\section{Contract-based energy goal (NC or R):}

An energy goal, stated in terms of absolute energy use, serves as a driver to achieve aggressive energy performance. Although parking consultants and design teams have been using sustainable practices for park-

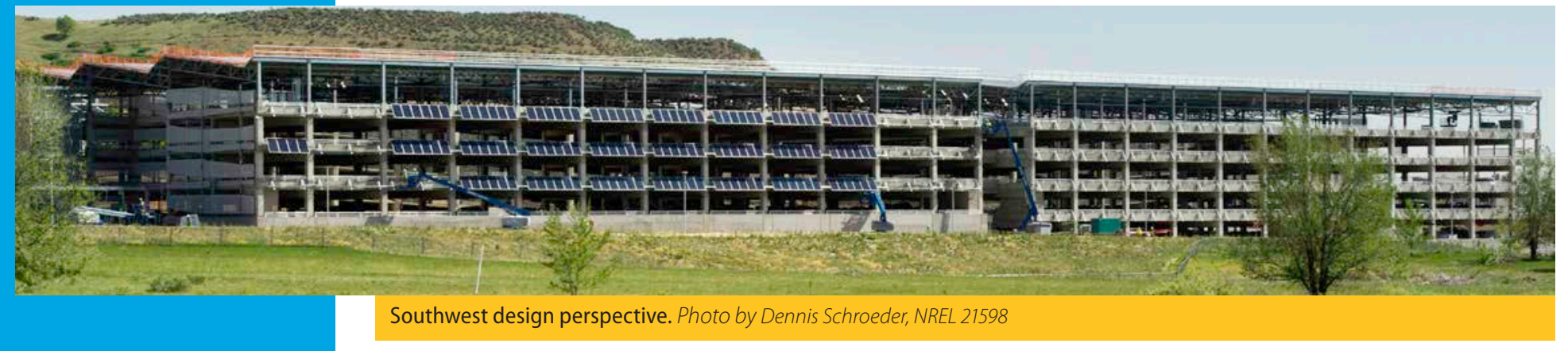

commercialbuildings@nrel.gov

www.nrel.gov/buildings/ commercial.html
' Calculation performed using ENERGY STAR ${ }^{\circledR}$ energy use intensity (EUI) rules of thumb (www.energystar.gov/index. cfm?fuseaction=building contest.eui) and ENERGY STAR Performance Ratings Technical Methodology for Parking (www.energystar.gov/ia/business/evaluate_performance/parking_tech_desc.pdf).

The NREL parking structure energy modeling reports, produced by M.E. GROUP, savings potential. A baseline structure for comparison accounts for lighting as defined by ASHRAE Standard 90.12007 (ASHRAE 2007). Natural ventilation and miscellaneous equipment remain the same between design case and baseline, although this guide provides design considerations for all systems. 


\section{Low-Energy Parking Structure Design}

Table 1. Design Consideration Summary

Typical Parking Structure

None.

Mechanical ventilation if underground or enclosed.

None (or at least no control of electric lighting in response to available daylight).

$0.18-0.30 \mathrm{~W} / \mathrm{ft}^{2}$ installed load. ${ }^{3}$

No occupancy or daylight controls.

Concern for safety and way finding.

Active heating methods to prevent

freezing in drainpipes and elevator gear.

Preferred parking.

None.

Commissioning but no measurement and verification (M\&V).

\section{Best Practices}

Natural ventilation only.

Daylight provides $75 \%-100 \%$ energy use reduction for electric lighting during daytime hours

$0.05-0.18 \mathrm{~W} / \mathrm{ft}^{2}$ installed load depending on illuminance requirements. Occupancy and daylight controls.

Concern for safety and way finding, driving time, and lighting use. Flow considerations reduce energy use by $75 \%$ during nighttime hours (can vary based on garage use patterns)

Passive heating and heat recovery methods to prevent freezing in drainpipes and elevator gear.

Preferred parking and onsite charging stations powered by renewable energy.

Solar electricity and wind used in appropriate climate zones.

Commissioning and ongoing $M \& V$.

Commissioning

\section{Design Considerations, continued}

ing structures in recent years, many do not calculate energy use as part of their standard practices. Energy accounting can make a case for key energy savings such as parking management and lighting controls.

- (NC) Develop a contract-based energy goal (DOE 2010) in kilowatthours/parking stall/year. A per-parking stall energy goal encourages space efficiency and prevents overdesign of nonparking areas. Nine steps for establishing low-energy goals are provided on pages 3 and 4.

- (NC or R) Include lighting quantity and quality expectations such as color temperature, life, and glare ratings. Review the DOE High-Efficiency Parking Structure Lighting Specification (PNNL 2010) for more information about suggested luminaire attributes. The specification can be used in its entirety or mined for relevant information to include in a luminaire or lighting design performance specification.

- (NC or R) Include other environmental aspects such as green roofs and porous pavers; for example, LEED has identified key environmen- tal aspects. Bicycle and public transportation integration can also be defined explicitly in the contract goals.

\section{Ventilation (NC and R)}

An estimated $50 \%{ }^{5}$ total structure energy savings is possible for a naturally ventilated structure compared to a mechanically ventilated baseline structure. A demand-controlled retrofit can save up to $90 \%$ for the ventilation system depending on the installation (PG\&E 2011).

- (NC) When the structure can be built above ground, ensure that a $20 \%$ open façade (ICC 2010) is maintained on two or more faces to facilitate $100 \%$ natural ventilation.

- (R) An open parking structure is not always possible. If the structure is placed partially or completely below ground, include methods such as areaways for partial natural ventilation (ICC 2010).

\footnotetext{
${ }^{3}$ The Illuminating Engineering Society of North America (IESNA 2000) Handbook provides illuminance criteria that can be easily met with the maximum ASHRAE 90.1 (ASHRAE 2007) allowance of $0.3 \mathrm{~W} / \mathrm{ft}^{2}$. The minimum illuminance recommendation is $1 \mathrm{fc}$. The IESNA Guideline for Security Lighting for People, Properties, and Public Spaces, G-1-03 (IESNA 2003), gives illuminance recommendations for enhanced security.
} 


\section{Low-Energy Parking Structure Design}

\section{Develop a Low Energy Goal for Parking Structures}

1. Select a lighting power density (LPD) based on needed illuminance (pay particular attention to uniformity during design per recommendations from Crime Prevention Through Environmental Design [CPTED] (International CPTED Association 2011). $\checkmark$

\section{Light Load Estimates for Setting an Energy Goal}

\section{LPD \\ $\left(\mathrm{W} / \mathrm{ft}^{2}\right)$

Typical
Illuminance $(\mathrm{fc})^{4}$

$\leq 1$

$\leq 0.05$

$1-5$

$7: 1$

$0.18-0.3$

$\geq 5$

10:1

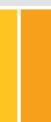

Notes

Lowest LPD of reviewed literature (www.energy.ca.gov/title24/ 2013standards/prerulemaking/documents/2011-04-04_workshop/ review/Nonres_Parking_Garage_Lighting_and_Controls.pdf), verified by lighting simulation.

CBEA High Efficiency Parking Structure Lighting specification maximum LPD (PNNL 2010).

The highest value of 0.30 is the ASHRAE 200790.1 (ASHRAE 2007) maximum LPD allowance.

${ }^{4}$ The typical illuminance and uniformity values are drawn from standards (PNNL 2010 and IESNA 2000) and verified with calculations but do not hold true for all design options. The pairings are meant to show that, in typical parking structure lighting layouts, when LPD decreases a uniformity increase is mandated by the need to maintain 1 footcandle (fC) (the minimum IESNA recommendation, IESNA 2000). In a more deterministic approach for pairing low LPD with improved lighting quality, the most recent IESNA parking structure lighting recommendations (IESNA 2011) emphasize luminance and uniformity. They also include considerations of adaptation and source color temperature when selecting illuminance design criteria.

2. Identify demand profiles of occupant types. Create a unique profile for each floor to determine whether loading schemes can prevent the use of full lighting on each floor for all occupied times. >

Example office occupancy profile > Example occupancy logging device $\checkmark$

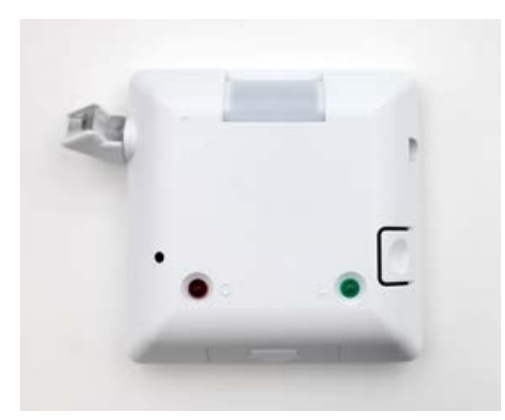

hoto by Jennifer Scheib, NREL/PIX 23056

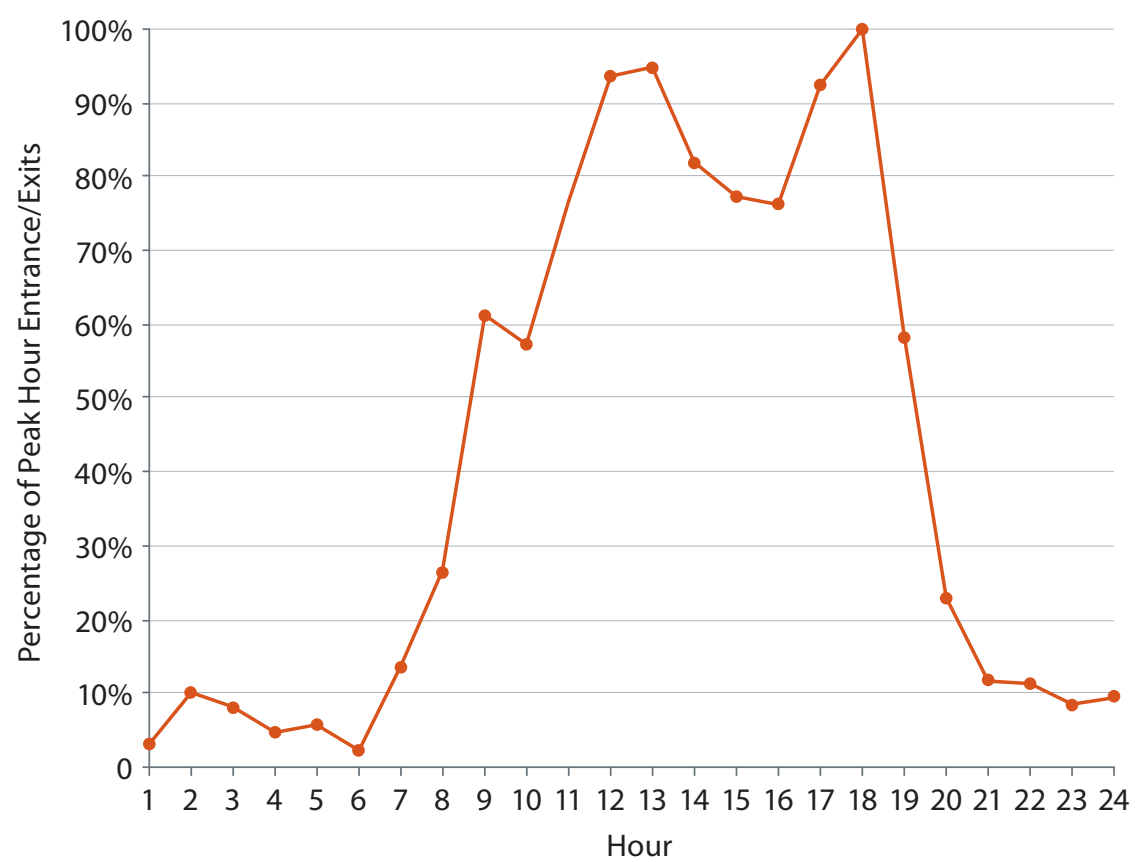

Tools for Determining the Potential of Time-Based Load Reduction 


\section{Low-Energy Parking Structure Design}

\section{Develop a Low Energy Goal for Parking Structures (continued from previous page)}

3. Estimate realistic daylighting potential for the site. Simulations or case studies such as the one in this guide can be used. Optimize form and orientation for energy efficiency within site constraints. >

Completely Open Structure Daylight
Illuminance (typical beam and floor
heights). Values in the table below are
the daylight illuminance values for the
area outlined in yellow

4. Multiply the potential LPD by the combined daylight and occupancy percentages.

5. Add energy use for security systems, elevators, and ventilation (weighted by a demand profile) as relevant to each structure.

6. Evaluate parasitic loads for transformers and control systems that might be selected for lighting, ventilation, and parking management.

7. Depending on your company's primary environmental concern, add energy or cost credits for solutions that reduce per-person total emissions.

8. Present a preliminary energy goal to proposing teams and request rigorous review to ensure the experts see the goal as achievable.

9. Require that the energy goal be substantiated throughout the design phases. Energy and daylight modeling are recommended to give the team confidence that the energy goal can be achieved. If modeling is not feasible, case study comparisons can be used.

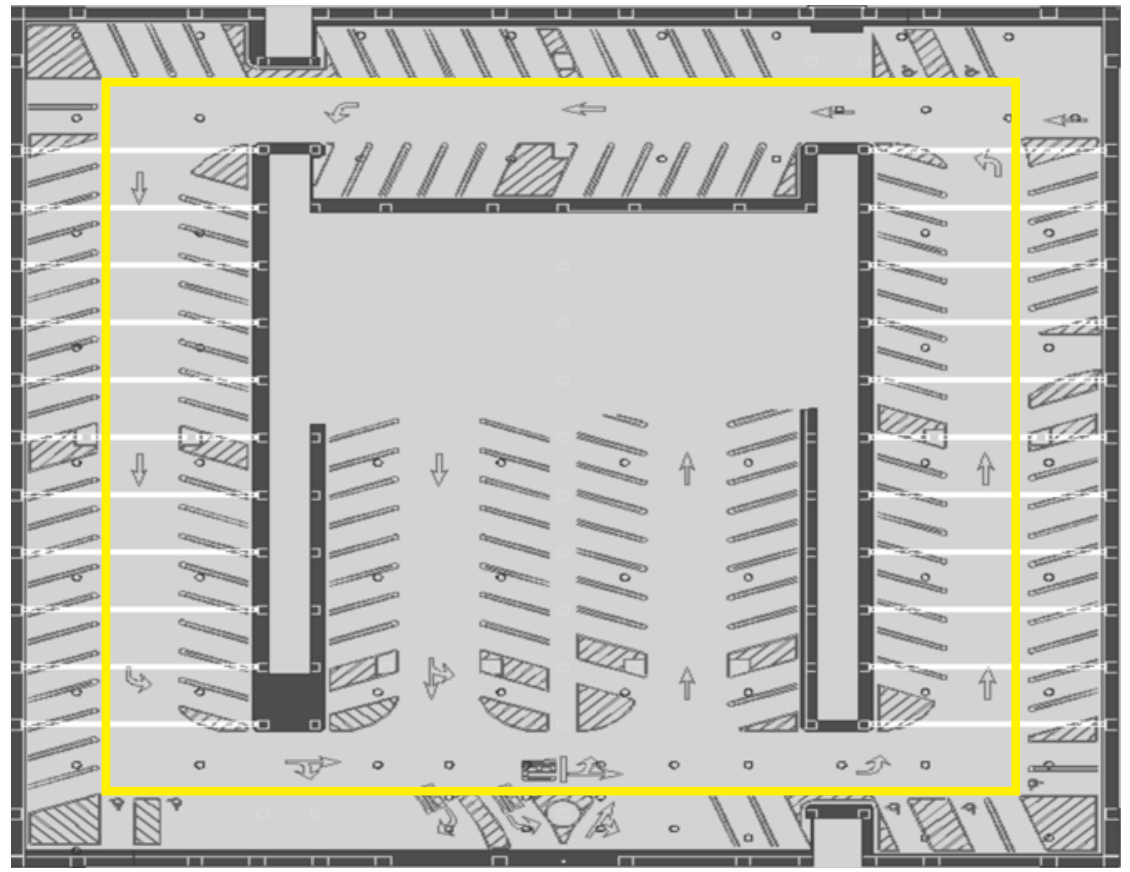

Sunny Climate Annual Average Illuminance (fc) at Floor

\begin{tabular}{|c|c|c|c|c|c|c|c|c|c|c|c|c|}
\hline 776 & 151 & 134 & 112 & 72 & 76 & 56 & 71 & 80 & 48 & 60 & 94 & 377 \\
\hline 481 & 69 & 86 & 35 & 28 & 27 & 28 & 29 & 25 & 26 & 31 & 46 & 119 \\
\hline 453 & 51 & 69 & 64 & 14 & 12 & 13 & 16 & 10 & 12 & 23 & 63 & 102 \\
\hline 150 & 44 & 24 & 58 & 6 & 7 & 6 & 6 & 4 & 8 & 48 & 64 & 331 \\
\hline 425 & 94 & 17 & 9 & 7 & 4 & 5 & 5 & 4 & 7 & 49 & 71 & 339 \\
\hline 740 & 97 & 68 & 7 & 8 & 2 & 5 & 2 & 6 & 6 & 52 & 41 & 347 \\
\hline 743 & 94 & 68 & 8 & 4 & 5 & 5 & 5 & 2 & 7 & 43 & 67 & 353 \\
\hline 746 & 90 & 64 & 56 & 5 & 4 & 2 & 2 & 4 & 4 & 47 & 70 & 346 \\
\hline 744 & 97 & 65 & 58 & 4 & 5 & 4 & 2 & 2 & 7 & 47 & 32 & 337 \\
\hline 744 & 103 & 73 & 11 & 14 & 9 & 8 & 1 & 1 & 6 & 49 & 35 & 113 \\
\hline 488 & 115 & 110 & 24 & 70 & 36 & 76 & 2 & 1 & 1 & 60 & 124 & 129 \\
\hline 789 & 166 & 105 & 134 & 64 & 74 & 107 & 111 & 71 & 100 & 55 & 91 & 446 \\
\hline 1195 & 593 & 543 & 542 & 249 & 680 & 665 & 612 & 567 & 196 & 549 & 589 & 495 \\
\hline
\end{tabular}

$\begin{array}{llllllllllllll}\text { (ft) } & 10 & 30 & 50 & 70 & 90 & 110 & 130 & 150 & 170 & 190 & 210 & 230 & 250\end{array}$ 
- (NC) Consider structure type and ramp location based on ventilation considerations.

- (R) When mechanical ventilation must be incorporated as a primary or backup system, use variable frequency drive, demand-controlled ventilation based on carbon monoxide sensors, or occupancy sensors where code permits.

\section{Daylighting (NC and R)}

For new construction, a $75 \%{ }^{6}$ daytime lighting energy savings is possible if the structure is optimized for daylight. If a 20 -foot perimeter zone is used for daylighting control in an existing parking structure, an estimated $25 \%$ daytime lighting energy savings can be realized.

- (NC) Minimize the distance to daylight by creating a narrow footprint or by adding light wells. Maximize façade openness by using cables for vehicle barriers, investigating light transmitting material options, and increasing floor-to-beam depth.

- (NC) Consider more complex daylight distribution systems such as optical louvers or fiber optic when there is limited freedom in footprint and structure type.

- (NC) Use light color pigments for concrete to maximize reflected daylight.

- (NC) Consider modeling daylighting options or reviewing case studies to gain confidence in daylight saturation in each electric lighting zone. Can at least 75\% of the lighting load be shut off with 1 fc minimum being maintained for $75 \%$ of the operating hours?

- Design structural elements so they allow as much daylight and natural ventilation as possible; pay special attention to beams near the perimeter.

- (NC) Design entrances so the IESNA visual adaptation recommendation of $50 \mathrm{fc}$ can be met with daylighting falloff instead of electric lighting.

\section{Electric lighting ( $\mathrm{NC}$ and $\mathrm{R}$ )}

An energy savings of $80 \%$ is possible versus an ASHRAE 90.12007 baseline for installed lighting load reduction alone.

- (NC or R) LPD values for parking structures are $0.05-0.30 \mathrm{~W} / \mathrm{ft}^{2}$. The low end is achievable for facilities that accept the low end of the typical IESNA illuminance criteria (IESNA 2000). Refer to criteria for mesopic adaptation (IESNA 2011) ${ }^{7}$, or use efficacious source and distribution systems such as light-emitting diodes (LEDs). Other parameters such as bay width and material reflectance will affect achievable LPD. The higher end will be needed for parking structures that have higher light level requirements and that need a less efficient distribution system.

- (NC or R) Consider control type when looking at the light source to ensure compatibility with likely selected occupancy sensors and daylight sensors (dimming versus switching). If the local code allows lighting to be switched off or dimmed to $10 \%$ output during unoccupied times, sources such as induction and LED should be selected instead of metal halide.

- (NC or R) Depending on the local code and the population served, on/ off switching might be unacceptable. The $90 \%$ total structure energy savings presented assumes that the bay lights can be turned off when the bays are unoccupied. If this is not an option, reduce the light output based on occupancy sensors. Load-reducing options such as bilevel switching, dimming to $10 \%$ light output, or dual switching between an occupied light source and unoccupied light source may be practical.

- (NC or R) Consider a variety of luminaire types such as those with a small uplight component, different mounting heights, and increased illuminance in areas that will help pedestrian and traffic flow. A slight decrease in fixture efficacy in key locations may improve overall structure lighting efficacy because wattage can be decreased in drive aisles or other less critical spaces. The lighting diversity can also increase occupant comfort and safety.

- (NC or R) Consider reflective paint for signage or ceiling elements to improve way finding and lighting distribution without adding electrically lighted signs or significant uplight components.

\section{Pedestrian and traffic flow (NC and R)}

A 75\% lighting energy savings is possible versus a structure that does not strategically direct vehicles (includes occupancy sensing technology and architecturally directed pedestrian paths). A 50\% lighting energy savings is likely for an existing structure that adds sensors to reduce the lighting load to $10 \%$ power during unoccupied times (CLTC 2010).

- (NC) Make stairs and walking paths central to the design to limit driving time and elevator use. Provide access to primary destinations off the main level to prevent added driving time to additional levels. Or use signage to influence loading and unloading patterns that limit driving time and triggering of occupancy sensors. Consider modeling to predict occupant behavior or use monitored behavior of the same population.

- (NC or R) Consider a parking management system if energy use or driving time can be reduced. Parking management can refer to policy and operational aspects such as access cards, payment methods, and surveillance. Here, parking management refers to methods for directing drivers to open spaces or preferred spaces to limit driving time and optimize lighting or ventilation use in certain areas. For example, an entire floor might have lighting and ventilation shut down during nonpeak parking times. Include primary and parasitic loads when evaluating the energy and emissions benefits of using a parking management system.

\section{Equipment (NC and R)}

An energy use savings of about 30\% can be achieved over a baseline equipment case. There are operations and maintenance benefits to using passive strategies.

- (NC) Use passive means for drainpipe and gear/utility room heating when possible.

- (NC) Use natural ventilation for gear or equipment rooms to offset fan load.

- (NC or R) Consider high-efficiency equipment such as security cameras without heaters, normally open relay gates, regenerative elevators,

\footnotetext{
This is a bounding case assuming a peak ventilation rate of $1.5 \mathrm{~cm} / \mathrm{ft}^{2}$ for all hours of operation.

${ }^{6}$ Daylighting savings are based on simulated and verified performance for the NREL parking structure case study.

The IESNA Lighting Handbook, Tenth Edition presents exterior lighting criteria with mesopic adaptation multipliers. The criteria should be considered for parking garages as long as low luminance scenarios (e.g., moderate to low surface reflectance, lensed light fixtures) can be achieved. If implemented properly, safety and security can also benefit from low but even illuminance and luminance distributions.
} 


\section{Low-Energy Parking Structure Design}

occupancy sensors on elevator lights, and guardhouses with heat recovery and occupancy sensors.

- (NC or R) Investigate variable refrigerant flow retrofit options or highefficiency heat pumps if elevators, guardhouses, or other occupied spaces need frequent heating or cooling.

- (NC or R) Require passive means for way finding (e.g., no illuminated signs or audible cues).

\section{Incentives (NC and R)}

Create ease of flow for all types of transportation to reduce carbon emissions inside and approaching the garage.

- (NC or R) Place carpool and low-emission vehicles in prime parking spots.

- (NC) Provide car charging through onsite renewable energy generation such as wind or solar, especially if peak charging demand matches peak energy production. Consider demand-control strategies, which balance the energy needs and resources of the parking structure (including electric vehicles and renewable energy sources) and any attached buildings the parking structure serves.

- (NC) Create a bicycle-friendly environment with adequate storage and gate pass-through options.

- (NC or R) Consider car sharing options if you have split occupancy between needing car use at night and during the day to reduce the structure's footprint. Credit should be given in energy goal-based contracts for creative solutions that reduce the footprint.

- (NC or R) Some recommended measures can be low cost or free, but others such as renewable energy systems can be cost prohibitive. Investigate utility and state or local energy efficiency incentives to defray added costs.

\section{Onsite renewable energy systems (NC and R)}

Renewable energy can offset the entire parking garage's and parts of adjacent buildings' annual energy use. Plan for current or future onsite renewable energy systems such as solar electric (PV) or wind in locations with a good resources by:

- Optimizing orientation for solar exposure for PV panels. Panel placement options include the structure's top level, roof, or an unshaded south façade. Be sure to design for any added wind or structural load and include the panel attachment method in the design. PV structures that provide weather protection could be considered an amenity. In cold climates, address the possibility of ice formation.

- Design the electrical system to accommodate a current or future onsite renewable energy system.

\section{Commissioning and M\&V (NC and R)}

Verify and maintain 90\% energy savings over an ASHRAE Standard 90.1 2007 baseline for new construction. Or for a retrofit, use a system-specific energy use (estimated from energy savings values given in this guide for the building's baseline conditions) as an operational goal to be verified.

- (NC or R) Inspect the design and installation of occupancy and daylight sensors under a variety of conditions to substantiate expected operation and estimates for energy savings. Check for false triggers between zones and floors, and test for sensor shadowing by columns or beams.

- (NC or R) Many assumptions will need to be made about occupancy-related energy savings (unless the occupant population was previously monitored), so $M \& V$ of the predicted energy savings will help inform system setting tweaks, retrofits, and future designs that can improve the current design or system settings.

- (NC or R) Meter lighting, mechanical ventilation (if required), onsite renewable energy, and miscellaneous electric loads separately so lighting can be closely watched and commissioned, tweaked, or rezoned (assuming a flexible control system is selected) as necessary.

\section{Case Study: National Renewable Energy Laboratory Parking Structure}

A new NREL parking structure was completed in February 2012 at a cost of $\$ 14,172$ /parking stall. The $550,000-\mathrm{ft}^{2}$, five-level structure has:

- Approximately 1,800 parking stalls oriented 90 degrees to the drive aisles

- 20 motorcycle stalls

- Accommodations for 30 bicycles.

The architectural layout originated and was refined based on low energy and sustainability concepts such as daylighting, natural ventilation, efficient loading and unloading schemes, and preferred parking organization. The structure includes:

- Cast-in-place, post-tensioned concrete base structure

- Steel frame canopy on top of the base structure that supports most of the PV

- Steel framing on the south façade that supports additional PV

- A bus shelter with bird-friendly (fritted) glazing

- Steel-framed stairs with bird-friendly (fritted) glazing.

\section{Performance specification}

- NREL set an annual energy goal of $51 \mathrm{kWh}$ /parking stall/year (approximately $0.15 \mathrm{kWh} / \mathrm{ft}^{2} / \mathrm{yr}$ ) based on best practices, best-in-class equipment options, and case study comparisons. The goal encompasses lighting, security, fans, parking management, and parasitic loads, but does not include electric vehicle charging. The proposing designbuild teams were given an energy appendix to the contract, which states the assumptions that led to the goal and provides guidelines for calculations in design. The team was given flexibility in choosing solutions as it met the performance requirements. No concerns were expressed about the goal assumptions in team preselection meetings, and all teams showed in their proposals preliminary calculations of how the goal could be met.

- A voluntary incentive program was provided to ensure that predicted and actual performance match according to an M\&V assessment. The program allows for superior, excellent, satisfactory, and unsatisfactory performance feedback from the owner. Topics such as safety, communication, and timeliness contribute to the overall performance rating; energy and sustainability issues are also given considerable weight. 

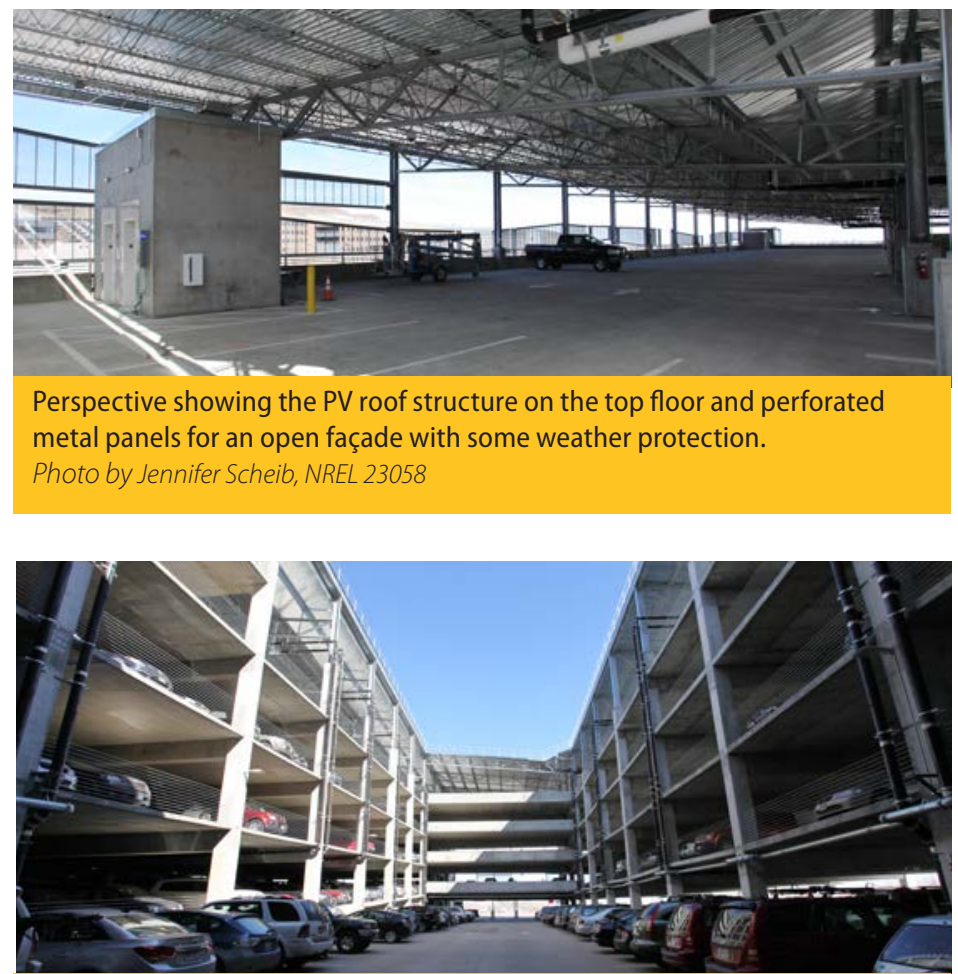

Light well perspective showing light-colored concrete and cable barriers for increased daylight saturation inside the structure.

Photo by Jennifer Scheib, NREL 23059

- In addition to the low energy specification, a contract requirement for the structure to be PV ready for more than $1 \mathrm{MW}$ allows the net zero energy goal for the supported office buildings to be met.

\section{Ventilation}

The energy goal was stringent enough to preclude mechanical ventilation for the entire structure. The design maintains an approximate $40 \%$ façade openness that allows natural ventilation on all levels.

\section{Daylighting}

Lighting is typically the largest load, particularly for naturally ventilated structures. To reduce the lighting load to almost zero during daylight hours, the façade is perforated metal with $40 \%$ openness, distributed to just meet headlight blockage and weather protection requirements. All remaining façade space is either open air or glass for enclosed stairs. The open façade would not be able to meet a full daylighting effort in the center of the space, so the structure has a light well on each side. The sloped terrain and tight construction schedule lent themselves to a split wing structure. An added benefit is that wings, in addition to floors, can be loaded first based on daylight availability. The footprint can be described as two, 325-foot zones connected by a large stair; each zone consists of four, 60-foot bays (two are typical parking bays, one is a light well, and the other is a parkable ramp). Daylight modeling shows, and operation substantiates, that only a few places in the structures, such as under the stairs, need to be electrically lighted between sunrise and sunset (based on $1 \mathrm{fc}$ minimum illuminance).

\section{Electric lighting}

The installed LPD is just under $0.05 \mathrm{~W} / \mathrm{ft}^{2}$. This is achieved with one, 71Watt LED fixture per bay (two-direction driving aisle with 90-degree park- ing stalls on both sides of the aisle) with additional lighting for stair and elevator areas. The lighting fixture provides the distribution necessary to meet the performance specifications of $1.5 \mathrm{fc}$ average, $1 \mathrm{fc}$ minimum, 4:1 average to minimum illuminance ratios (without cars), and reduced glare potential, similar to recommendations in the High-Efficiency Parking Structure Lighting Specification (PNNL 2010).

The electric lighting is controlled by strategically placed daylight sensors and occupancy sensors. Occupancy sensors are infrared type and will take the lights to full off when no occupancy is detected. Light fixtures are zoned to provide a pathway of light for each entering occupant. An advanced lighting control system will allow for ease of commissioning and retrocommissioning by convenient regrouping and assigning fixtures and sensors, depending on occupant patterns. Emergency lights are on a generator, so battery backup is not needed. Fail-to-On mechanisms are installed.

\section{Pedestrian flow}

At the beginning of the day, drivers enter the structure on the first or second floor, depending on the side, and are directed by a parking management system (induction loop car counters and LED signs) to floors. The parking management system has the capability to direct the drivers to fill the upper and lower floors to save the first floor for late arrivals. The top-down loading can reduce lighting loads at night because later arrivals (typically later departures) will use first-floor resources only. A central stair that is inviting and well daylighted is provided to encourage stair use versus elevator use. Two elevators are provided at the stairs (also the connection to the bus shelter). A structure of this size would typically have more than two elevators.

\section{Equipment}

Miscellaneous equipment includes fans for equipment rooms, elevator lighting and ventilation, phones and cameras for security, heat trace for drainpipes, heaters for cameras and fire alarm pull stations, and lighting and fire alarm controls. The estimated annual energy use breakdowns for elevators and miscellaneous equipment are $16 \%$ and $55 \%$, respectively. The remaining $29 \%$ is estimated for lighting. The high miscellaneous electric load is due largely to security equipment, which consumes $29 \%$ of the total annual energy. This level of security might not be necessary for some facilities.

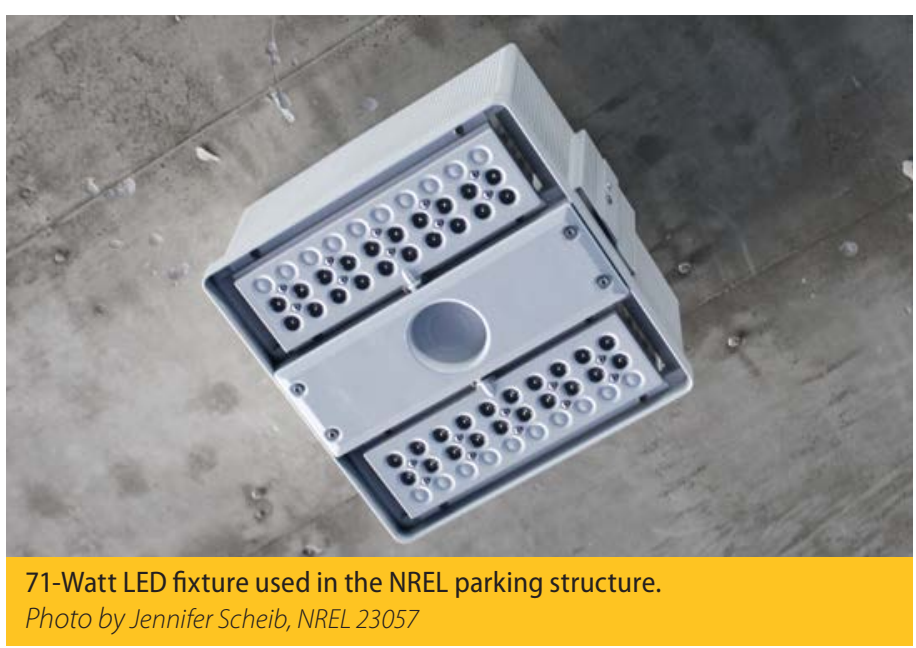



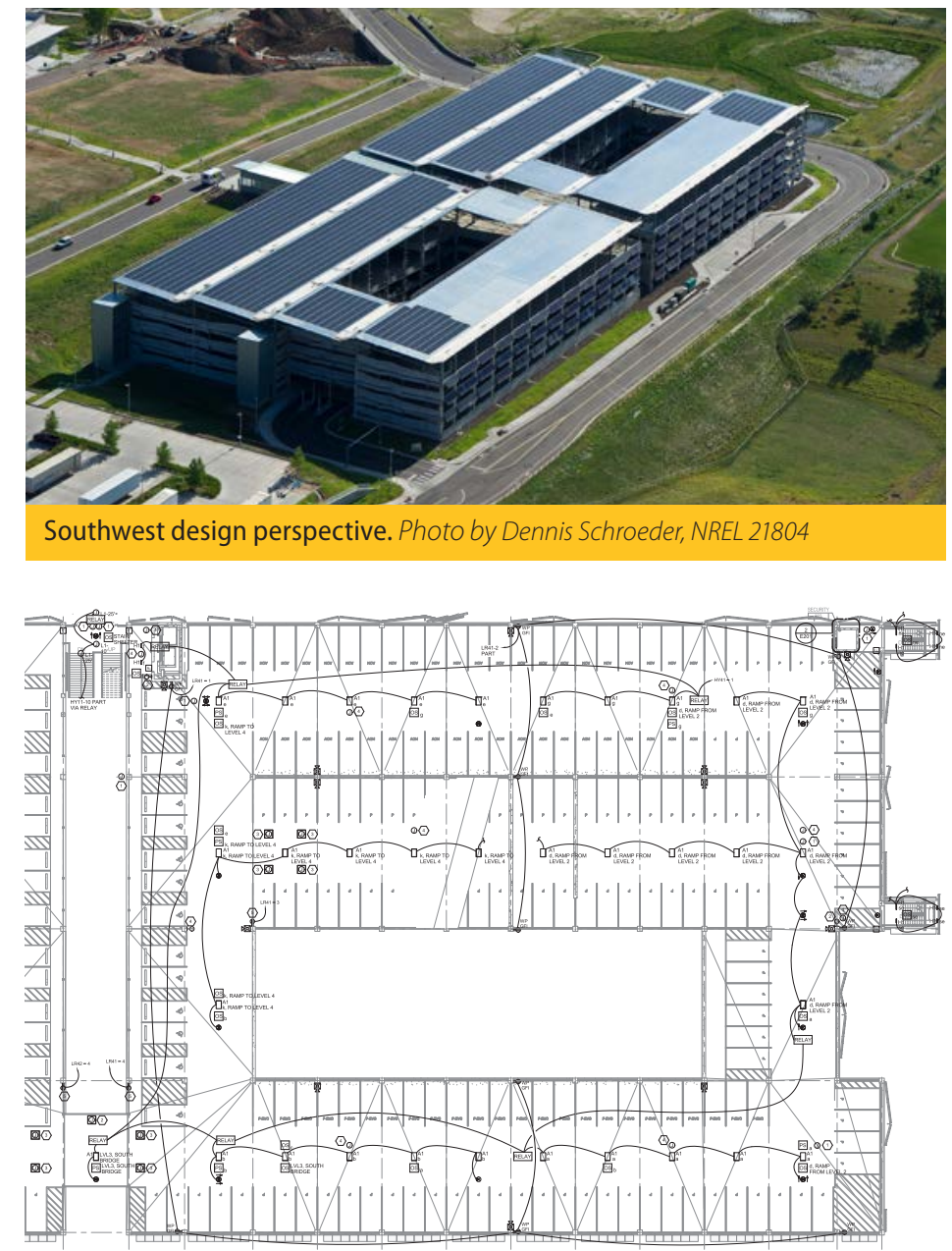

Third level lighting plan, east half, including central stair. Illustration from RNL Design and M.E. GROUP

\section{Incentives}

Sustainability incentives include preferred parking for low-emission vehicles, carpools, and electric vehicles. Thirty-six electric vehicle charging stations are currently available with intention to add up to 330 throughout the life of the structure. Biker-friendly access gates at the nearby campus entrance and lockers in the bus shelter encourage its use as a transportation hub.

\section{Onsite renewable energy systems}

As described in the project summary, PV panels are located on a superstructure above the top parking level and on supports providing an optimal panel tilt on the south façade. The 1.1-MW installed resource will provide just under half the energy necessary to offset a supported office complex to net zero energy. The structure has capacity for more than 1.4 MW of PV.

\section{Commissioning}

The lighting, parking management, and security systems will be commissioned using a system sample approach. Lighting system checks will help ensure the occupancy sensors are sensitive enough to trigger light for entering occupants and for occupants rounding corners, without false triggers caused by occupants in nearby bays.

The structure's attributes lead to an estimated energy use of $42 \mathrm{kWh} /$ parking stall, which is below the contract goal and is a $90 \%$ reduction from an ASHRAE 90.12007 baseline (lighting is the only system that changes between baseline and design). The execution of detailed specifications and commissioning resulted in operational success. M\&V using end use metering as a guide will help verify and tune energy use to realize the energy goal. References $\nabla$

\section{References}

ASHRAE. 2007. ANSI/ASHRAE/IES Standard 90.1-2007, Energy Standard for Buildings Except Low-Rise Residential Buildings. Atlanta, GA: American Society of Heating, Refrigeration and Air-Conditioning Engineers.

CLTC. 2010. Bi-Level Induction Parking Garage Luminaires. Davis, CA: California Technology Lighting Center. http://cltc.ucdavis.edu/images/ documents/case_studies/ucd\%20induction\%20final.pdf.

DOE. 2010. Getting to Net Zero Today Through a Performance-Based Design/Build Process. Washington, D.C.: U.S. Department of Energy. http://apps1.eere.energy.gov/buildings/publications/pdfs/corporate/ ns/webinar_rsf_03182010.pdf.

IESNA. 2000. The Lighting Handbook. Ninth Edition. Reference and Application. New York, NY: Illuminating Engineering Society of North America.

IESNA. 2003. Guideline for Security Lighting for People, Property, and Public Spaces. New York, NY: Illuminating Engineering Society of North America.

IESNA. 2011. The Lighting Handbook. Tenth Edition. Reference and Application. New York, NY: Illuminating Engineering Society of North America.

International CPTED Association. 2011. www.cpted.net/.

ICC. 2010. International Building Code. Falls Church, VA: International Code Council.

McDonald, S.S. 2009. "Parking Facilities." Whole Building Design Guide. www.wbdg.org/design/parking.php.

PG\&E. 2011. Codes and Standards Enhancement Initiative.

Garage Exhaust. San Francisco, CA: Pacific Gas \& Electric. www.energy.ca.gov/title24/2013standards/prerulemaking/documents/current/ Reports/Nonresidential/Covered_Processes/2013_CASE_ASHRAE8GarageExhaust_09.30.2011.pdf.

PNNL. 2010. Commercial Building Energy Alliance High-Efficiency Parking Structure Lighting Specification. Richland, WA: Pacific Northwest National Laboratory. www1.eere.energy.gov/buildings/commercial/cbea_parking_structure_spec.html.
National Renewable Energy Laboratory 15013 Denver West Parkway, Golden, CO 80401 303-275-3000 • www.nrel.gov
NREL is a national laboratory of the U.S. Department of Energy Office of Energy Efficiency and Renewable Energy Operated by the Alliance for Sustainable Energy, LLC NREL/BR-5500-52025 • January 2013 